\title{
Article \\ Recent Development and Future Perspectives of Quality Control and Assurance for the Deep Mixing Method
}

\author{
Masaki Kitazume
}

Citation: Kitazume, M. Recent Development and Future

Perspectives of Quality Control and Assurance for the Deep Mixing Method. Appl. Sci. 2021, 11, 9155. https://doi.org/10.3390/app11199155

Academic Editors: António Alberto Santos Correia and Paulo José da Venda Oliveira

Received: 30 July 2021

Accepted: 25 September 2021

Published: 1 October 2021

Publisher's Note: MDPI stays neutral with regard to jurisdictional claims in published maps and institutional affiliations.

Copyright: (C) 2021 by the author. Licensee MDPI, Basel, Switzerland. This article is an open access article distributed under the terms and conditions of the Creative Commons Attribution (CC BY) license (https:// creativecommons.org/licenses/by/ $4.0 /)$.
Department of Civil and Environmental Engineering, Tokyo Institute of Technology, Tokyo 152-8550, Japan; kitazume@cv.titech.ac.jp

\begin{abstract}
The deep mixing method (DMM), an in situ soil stabilization technique, was developed in Japan and Nordic countries in the 1970s and has gained increased popularity in many countries. The quality of stabilized soil depends upon many factors, including its type and condition, the type and amount of binder, and the production process. Quality control and quality assurance (QC/QA) practices focus on stabilized soil, and comprises laboratory mix tests, field trial tests, monitoring and controlling construction parameters, and verification. QC/QA is one of the major concerns for clients and engineers who have less experience with the relevant technologies. In this manuscript, the importance of QC/QA-related activities along the workflow of deep mixing projects is emphasized based on the Japanese experience/results with mechanical mixing technology by vertical shaft mixing tools with horizontal rotating circular mixing blade. The current and recent developments of QC/QA are also presented.
\end{abstract}

Keywords: quality control; quality assurance; deep mixing method

\section{Introduction}

The deep mixing method, an in situ soil admixture stabilization technique using cement and/or lime, was developed and put into practice in Japan and Nordic countries in the 1970s. Due to its wide applicability and high improvement effect, the method spread worldwide. More than two decades of practice have seen the equipment improved, stabilizing agents changed, and the applications diversified [1]. The quality of stabilized soil depends upon the type and condition of the soil, the type and amount of binder, and the production process. Quality control and quality assurance (QC/QA) practices have been accepted worldwide for more than five decades [2]. They are comprised of laboratory mix tests, field trial tests, monitoring and control of construction parameters during production, and verification by the engineering characteristics of stabilized soil.

The purpose of deep mixing is not only to produce good-quality stabilized soil, but also to construct improved ground that guarantees the performance of the superstructure. The ground improved by the method is a composite system comprising stabilized soil columns and original soils [1]. Construction control parameters during production include the penetration and withdrawal speeds of the mixing shaft, rotation speed of the mixing blade, flow rate of the binder, and water/binder ratio (for the wet method). However, the field-stabilized soil strength has relatively large variability, even if the production adheres to the established mixing machine and procedure. One of the reasons behind the strength variability is the type of soil. Some cohesive soils are so "sticky" that the soil and binder mixture adheres to and rotates with the mixing blade without efficient mixing (entrained rotation phenomenon). Several approaches can be adopted for such soils: new type special cement, injecting chemical additives, and injecting air.

In this manuscript, the recent development and future perspective of the QC/QA procedures are briefly discussed based on the Japanese experience/results with mechanical mixing technology by vertical shaft mixing tools with horizontal rotating circular mixing blade, as well as the countermeasures for problematic soils. 


\section{Deep Mixing Method}

\subsection{Classification of Techniques}

There are a wide variety of technologies classified into the deep mixing methods: the mixing by vertical shaft mixing tools with horizontal rotating circular mixing blade, and the mixing by horizontal shaft mixing tools with vertical rotating circular mixing blade. The quality control and assurance is different in each technology. The former technology is focused on in this manuscript. The Japanese deep mixing method can be classified into mechanical mixing, high-pressure injection, and the combination of mechanical and high-pressure injection, as shown in Figure 1. In mechanical mixing, a binder is injected into the original ground and mixed by the mixing blades. The binder is used either with a slurry [3] or dry form [4]. In the high-pressure injection technique, the original ground is disturbed and softened by high-pressure injection of water and/or air at a pressure of 10 to $60 \mathrm{MN} / \mathrm{m}^{2}$, while the binder is injected and mixed with soil. The third technique exploits the features of both mechanical mixing and high-pressure injection [5]. In this manuscript, the quality control and assurance of the mechanical mixing technique is introduced.

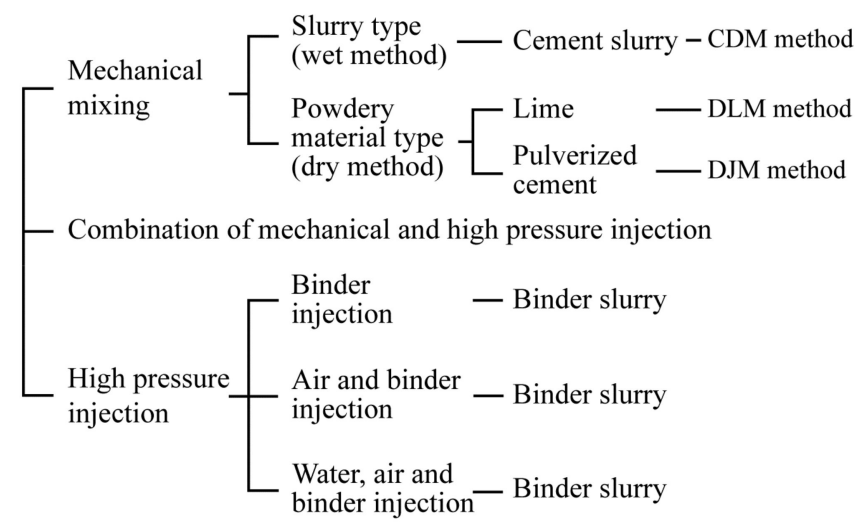

Figure 1. Classification of the Deep Mixing Method.

\subsection{Production Procedure}

There are two construction procedures which primarily depend on the injection sequence of binder (Figure 2): (a) injecting binder during the penetration of a mixing tool (penetration injection method) and (b) injecting binder during the withdrawal of a mixing tool (withdrawal injection method). Many Japanese deep mixing equipment install the two injection nozzles for the two methods. The injection nozzle, installed close to the lowermost mixing blades, is used for the penetration injection, but one installed close to the uppermost mixing blade is used for the withdrawal injection. In the case of the penetration injection, the mixing blades cut and disturb the soft soil, and the binder was injected at a constant flow rate during the penetration of the mixing tools into the ground. In the withdrawal stage, the mixing blades rotate reversibly, and mix the soft soil and binder again. In the case of the withdrawal injection, the mixing blades cut and disturb the soft soil during the penetration of the mixing tools into the ground, and the binder was injected at a constant flow rate and mixed the soft soil in the withdrawal stage. 


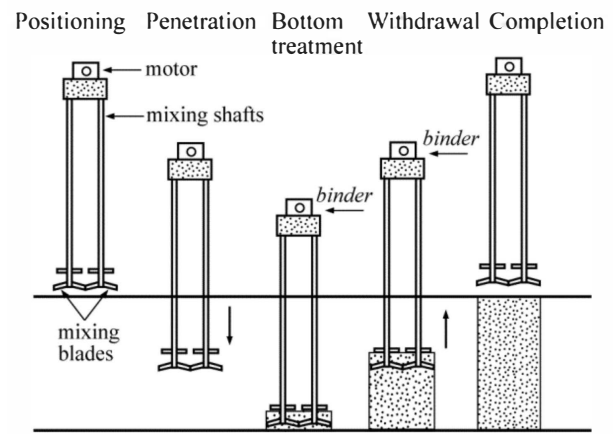

(a)

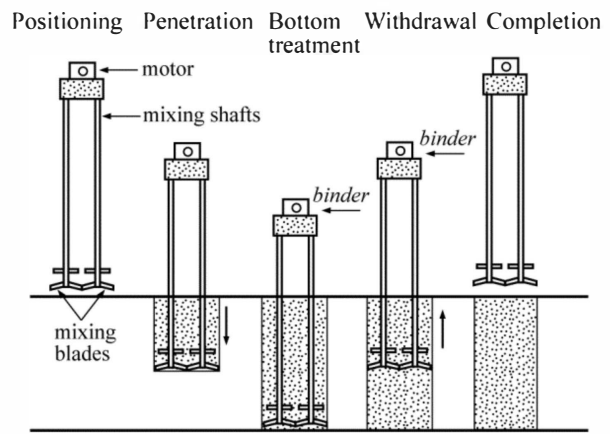

(b)

Figure 2. Production of the DM-stabilized soil column. (a) Penetration injection method; (b) withdrawal injection method.

\section{Laboratory, Field, and Design Strengths}

As the field mixing and curing conditions are quite different from the laboratory mix test, the field-stabilized soil strength is usually different from the laboratory-stabilized soil strength. The field-stabilized soil has a relatively large strength variability. The average strength, $\overline{q_{u l}}$, and deviation of the laboratory stabilized soil and the average strength, $\overline{q_{u f}}$, and deviation of field stabilized soil are schematically shown in Figure 3. The design standard strength, $q_{u c k}$, is derived from $\overline{q_{u f}}$ by incorporating the strength deviation as Equations (1) and (2). The magnitude of the parameter $K$ can be determined by the probability, which is defined as the frequency of the strength lower than the $q_{u c k}$, as a portion drawn with a hatch in Figure 3.

$$
\begin{gathered}
q_{u c k} \leq \overline{q_{u f}}-K \cdot \sigma \\
\overline{q_{u f}}=\lambda \cdot \overline{q_{u l}}
\end{gathered}
$$

where $K=$ coefficient, $q_{u c k}=$ design standard strength $(\mathrm{kPa}), \overline{q_{u f}}=$ average unconfined compressive strength of field stabilized soil $(\mathrm{kPa}), \overline{q_{u l}}=$ average unconfined compressive strength of laboratory stabilized soil $(\mathrm{kPa}), \sigma=$ standard deviation of field strength $(\mathrm{kPa})$, and $\lambda=$ ratio of $\overline{q_{u f}} / \overline{q_{u l}}$.

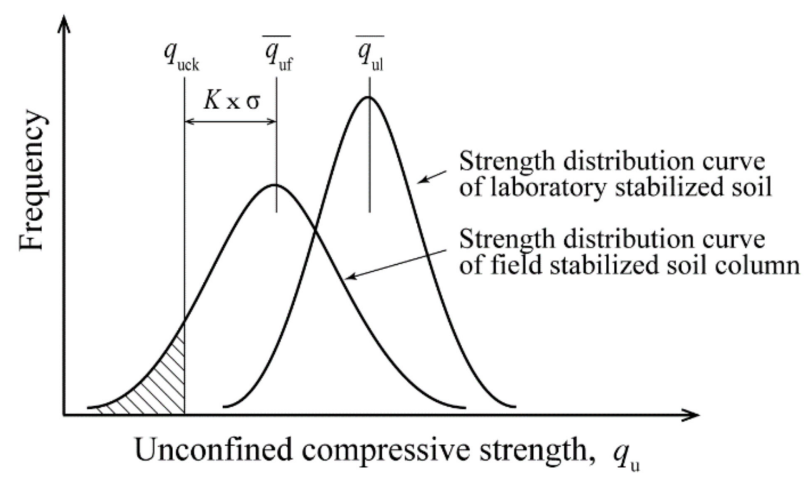

Figure 3. Field and laboratory strengths of stabilized soils.

\section{Flow of the Deep Mixing Project and QC/QA}

\subsection{Dep Mixing Project Work Flow}

Quality assurance to fulfill the requirements of geotechnical design cannot only be achieved by process control during production, but should involve relevant activities that are carried out prior to, during, and after construction.

$\mathrm{QC} / \mathrm{QA}$ is one of the major concerns for clients and engineers who have less experience with the deep mixing technique. The procedure of the geotechnical design is different 
depending on the application, and the construction control parameters and values are also different for different construction equipment. However, the overall workflow shown in Figure 4 (after [6]) is common to deep mixing projects. In the figure, the project owner's functions are shown in white frame, activities related to the geotechnical design are in slight gray frame, activities related to the process design and actual production with QC are in light gray frame, and accumulated experience and database on locally available production processes is shown in gray frame.

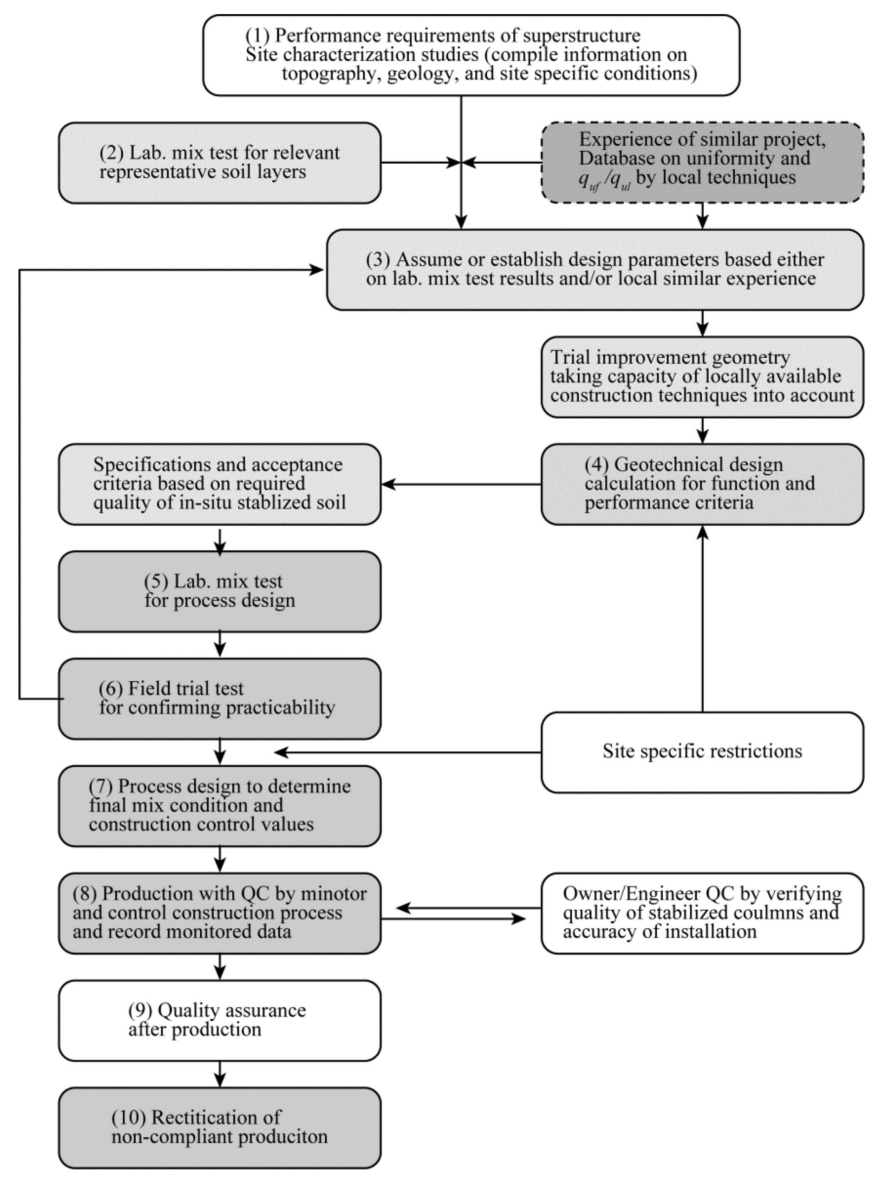

Figure 4. Flow of the deep mixing project and QC/QA (after [6]).

\subsection{QC/QA for Stabilized Soil-Current Practice}

To ensure sufficient quality of the stabilized soil column, quality control and quality assurance are required prior to, during, and after production. For this purpose, QC consists of (i) laboratory mix tests, (ii) field trial tests, (iii) quality control during construction, and (iv) quality assurance after construction through laboratory tests on core samples.

\subsubsection{Laboratory Mix Test}

Laboratory mix tests should be conducted on soil samples retrieved from all soil layers to be stabilized to determine a suitable type and quantity of binder to ensure the design strength.

\subsubsection{Field Trial Test}

Field trial tests are an important preproduction QA, especially when no comparable experience is available. It is recommended to conduct field trial tests in advance in or adjacent to the construction site to confirm the actual field strength and uniformity and determine the construction control parameters and final mix design for production. The change in electric or hydraulic power consumption, change in torque, and/or change 
in penetration speed are measured to establish the construction control criteria for the bottom treatment.

\subsubsection{Quality Control during Production}

Stabilized soil columns must be produced to satisfy the specified geometric layout and quality of stabilized soil. The rig operator should control, monitor, and record the geometric layout of each column.

As shown in Figure 5, the operation monitoring covers the quality and quantity control monitoring. The gauges and meters normally used are marked 1 to 8 in Figure 5.

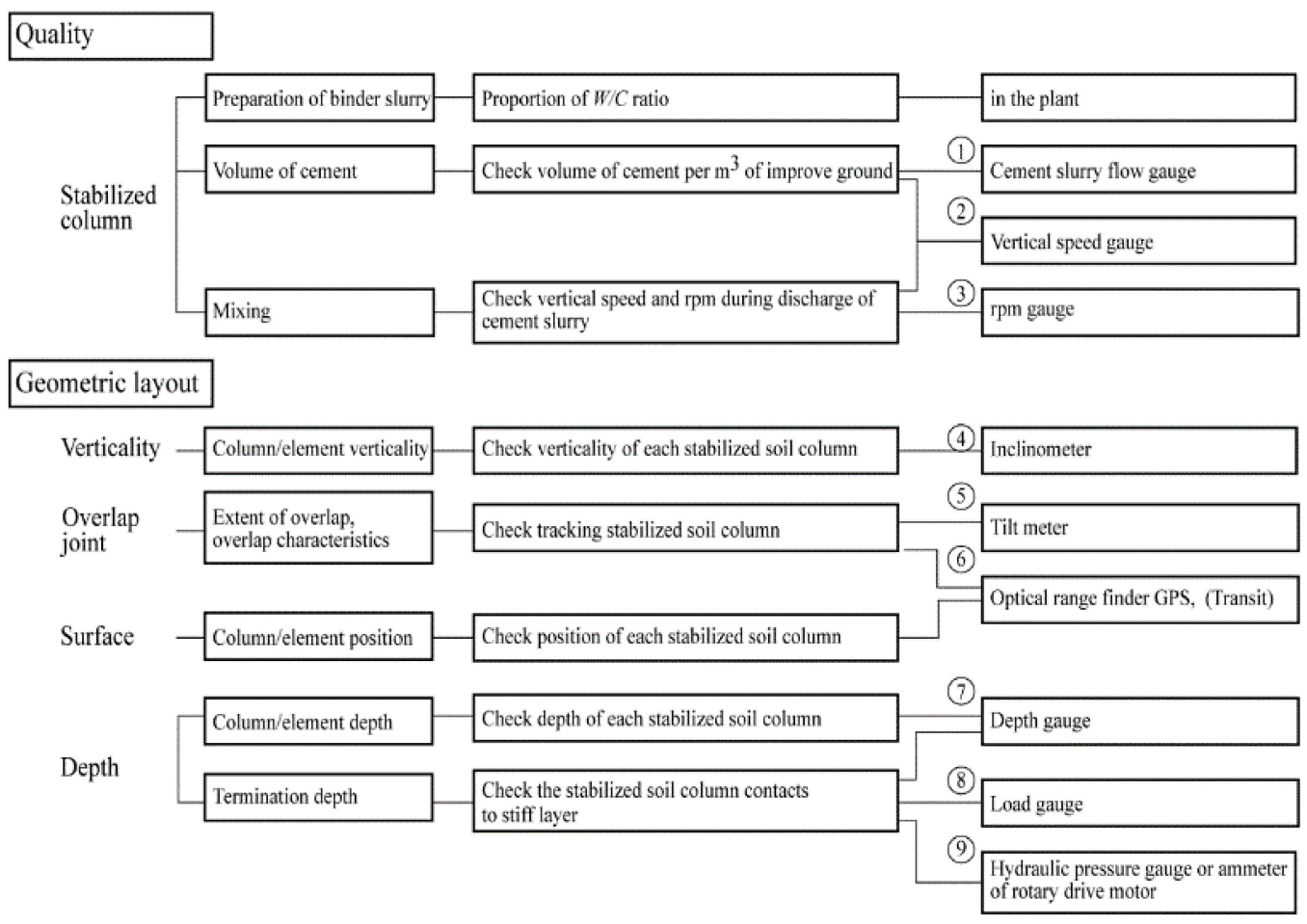

Figure 5. Operation monitoring for the CDM method on land works (after [3]).

Quality control also includes binder storage, binder slurry preparation, and control of the mixing process. Storage and proportioning of binder, chemical additives, and mixing water are normally controlled, monitored, and recorded at the plant. Construction control parameters during column production include the penetration and withdrawal speeds, rotation speed of the mixing blade, flow rate of the binder, and water/binder ratio (for the wet method). The construction control values are predetermined by the process design considering the laboratory mix test result, field trial test, and contractors' experience. During column production, construction control values are controlled, monitored, and displayed in the control room for the plant and rig operators. The mixing shaft and blade should be frequently observed for any possible defects during production.

The mixing degree mostly depends on the rotation speed and the penetration and withdrawal speeds of the mixing blade. An index named "blade rotation number", $T$, has been introduced to evaluate the mixing degree, which means the total number of mixing blade passes during $1 \mathrm{~m}$ of mixing shaft movement, and is defined by Equations (3) and (4) for penetration injection and withdrawal injection. According to accumulated research, the "blade rotation number" should be approximately 270 or larger to ensure sufficient mixing for Japanese wet and dry methods $[3,7,8]$.

$$
T=\sum M \cdot\left(\frac{N_{\mathrm{d}}}{V_{\mathrm{d}}}+\frac{N_{\mathrm{u}}}{V_{\mathrm{u}}}\right) \text { for penetration injection }
$$




$$
T=\sum M \cdot\left(\frac{N_{\mathrm{u}}}{V_{\mathrm{u}}}\right) \text { for withdrawal injection }
$$

where $N_{\mathrm{d}}=$ number of rotations of the mixing blade during penetration $(\mathrm{N} / \mathrm{min}), N_{\mathrm{u}}=$ number of rotations of the mixing blade during withdrawal $(\mathrm{N} / \mathrm{min}), T=$ blade rotation number $(\mathrm{N} / \mathrm{m}), V_{\mathrm{d}}=$ penetration speed of the mixing blade $(\mathrm{m} / \mathrm{min}), V_{\mathrm{u}}=$ withdrawal speed of the mixing blade $(\mathrm{m} / \mathrm{min})$, and $\Sigma M=$ total number of mixing blades.

\subsubsection{Quality Verification}

After the improvement, the quality of field-stabilized soil columns should be verified in advance of the construction of superstructures to confirm the design quality, such as continuity, uniformity, strength, permeability, or dimension. Core samples were taken throughout the depth to verify the uniformity and continuity of the stabilized soil column (Figure 6). The engineering properties of the stabilized soil are evaluated by the unconfined compressive strength of the core samples.

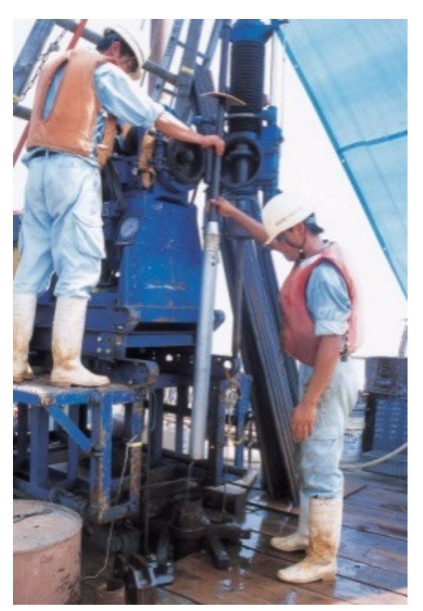

Figure 6. Core boring machine.

The reliability and accuracy of the unconfined compressive strength of the core sample depends upon the quality of the core sample, and the quality of the sample depends upon the drilling and coring method and drillers' skill. The Denison-type sampler, double tube core sampler, or triple tube core sampler can be used for stabilized soil columns whose unconfined compressive strength ranges from 100 to $6000 \mathrm{kPa}$. It is advisable to use samplers of a relatively large diameter to take high-quality samples. The quality of the retrieved core is evaluated by visual observation and the rock quality designation $(R Q D)$ iindex. The $R Q D$ index is defined by Equation (5). The $R Q D$ index measures the percentage of "good rock" within a borehole and provides the rock quality. The RQD index was originally applied for evaluating the quality of rock sample, as shown in Table 1.

$$
R Q D=\frac{\sum \text { length of core pieces }>10 \mathrm{~cm}}{\text { Total core run length }} \cdot 100(\%)
$$

Table 1. $R Q D$ index and rock quality (Deere, 1989).

\begin{tabular}{cc}
\hline$R Q D$ & Description of Rock Quality \\
\hline $0-25 \%$ & Very poor \\
$25-50 \%$ & Poor \\
$50-75 \%$ & Fair \\
$75-90 \%$ & Good \\
$90-100 \%$ & Excellent \\
\hline
\end{tabular}


A variety of verification test procedures to examine the engineering characteristics of stabilized soil have been proposed [9-11]. However, actual practices rely upon the unconfined compression test on core samples. Most of the other procedures seem to be used only for research purposes or settling noncompliance.

\section{Problems Associated with Difficult Soil Conditions}

\subsection{Stabilized Soil Strength Variability}

The field-stabilized soil columns have relatively large strength variability. One of the reasons behind the strength variability is the type of soil. Some cohesive soils are so sticky that the soil and binder mixture adheres to and rotates with the mixing blade without an efficient mixing "entrained mixing phenomenon", a condition in which disturbed soil adheres to and rotates with the mixing blades, as shown in Figure 7.

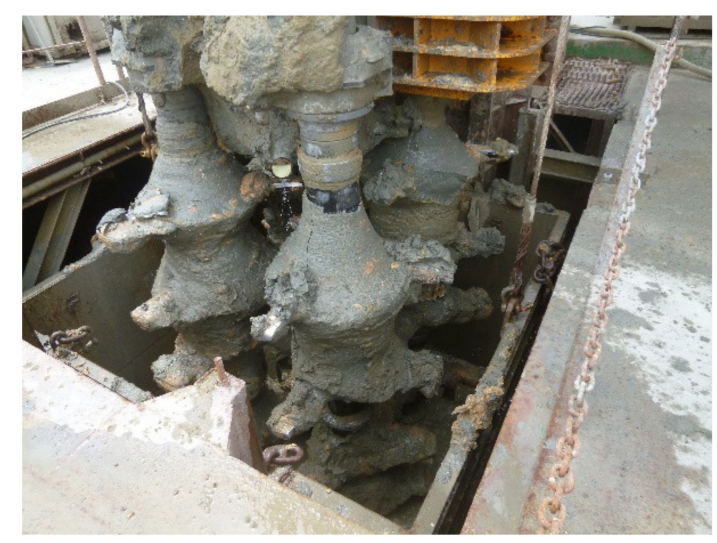

Figure 7. Example of "entrained mixing phenomenon".

When encountering stiff, cohesive, and sticky soil, water is often injected from the bottom outlet of the mixing shaft to increase the fluidity of the original soil. Water injection may be effective in increasing the fluidity of the original soil, but its effect is limited for some types of soil. However, water injection causes a decrease in the long-term stabilized soil strength and increases the ground heaving and horizontal movement during column installation. Several alternative approaches will be introduced in the following section: using a new type of special cement, and injecting chemical additives and air.

\subsection{Using the New Type of Special Cement}

Aoyama et al. [12] produced two special cements to stabilize cohesive soils that suppress short-term strength increases while guaranteeing long-term strength: Cement-A prevents electrostatic repulsion by negative charges to maintain fluidity, and Cement-B prevents electrostatic repulsion and polyvalent metal ions. Cement- $A$ and Cement-B are mixed with soils $\mathrm{T}$ and $\mathrm{V}$, respectively. The soil $\mathrm{T}$ (fines content less than $5 \mu \mathrm{m}, F_{c}$ of $49 \%$, and fines content less than $75 \mu \mathrm{m}, F s$ of $66 \%$ ) contains a large amount of clay minerals and has a large cation exchange capacity, and the soil V ( $F \mathcal{C}$ of $53 \%$ and $F s$ of $99 \%)$ contains a large amount of polyvalent metal ions.

Figure $8 \mathrm{a}$ shows the shear strength of fresh stabilized soil measured by a hand vane apparatus. The strength of soil stabilized with ordinary Portland cement increases with time soon after mixing, which corresponds to the decrease in the fluidity of the soil and binder mixture. The stabilized soil with Cement-A shows almost no strength gains, even 60 min after mixing, which indicates that the fluidity of the soil and binder mixture is kept high. A similar phenomenon can be seen in Figure 8b, where the stabilized soil with ordinary Portland cement increases in strength, but one with Cement-B shows a slight increase in strength. It should be noted in the figure that soil V stabilized with Cement-A also shows a large strength gain, while slight strength increases were observed in the case 
of soil $\mathrm{T}$. These results indicate that the strength increase in fresh stabilized soil can be suppressed for about one hour by adding chemical substances appropriate for the soil type.

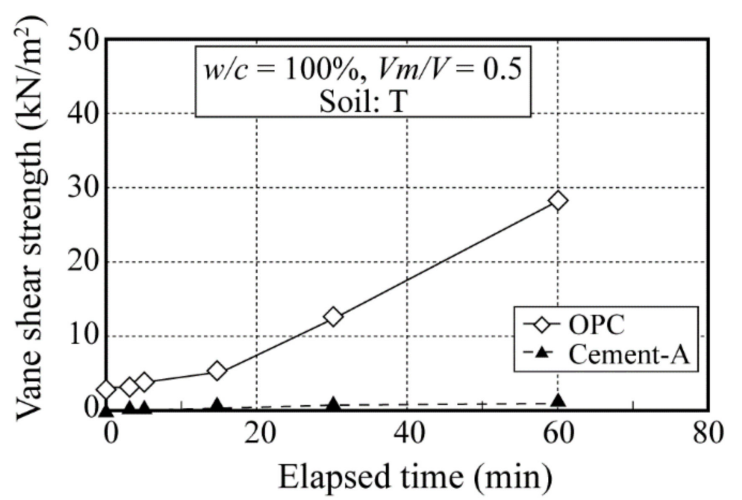

(a)

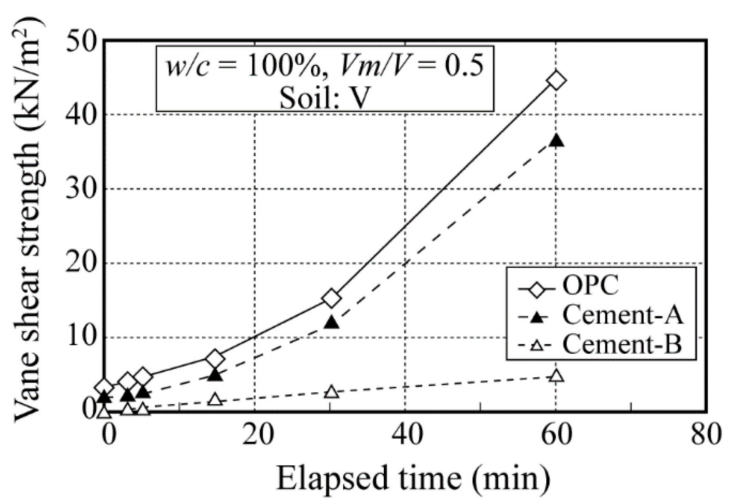

(b)

Figure 8. Increase in strength of the soil and cement mixture [12]. (a) Fresh stabilized soil, T; (b) fresh stabilized soil, V.

\subsection{Adding Dispersant}

Mizutani et al. [13] and Hirano et al. [14] showed the effect of two dispersants on the fluidity of soil and cement mixtures, where three types of soil, (1) artificial soil composed of kaolin clay (70\%) and silica sand (30\%), (2) artificial soil composed of kaolin clay (40\%) and silica sand $(60 \%)$, and (3) volcanic soil, were stabilized with cement-based special binder [15] mixed with dispersant. The shear strength of the fresh soil and cement mixture measured by a hand vane apparatus is shown in Figure 9. In the case of the glycolic acid dispersant (Figure 9a), the shear strength of the fresh soil cement mixture remained quite small by a very small amount of addition, and was almost constant within $60 \mathrm{~min}$, remaining almost unaffected by the amount of addition. However, the shear strength increased rapidly with the elapsed time when nothing was added. In the case of the polycarboxylic acid dispersant (Figure 9b), the strength of the mixture was smaller than that of the mixture without dispersant and increased with elapsed time. According to these figures, the glycolic acid and polycarboxylic acid dispersant function to keep the fluidity of the soil and binder mixture high soon after mixing. It can thus be concluded that the addition of suitable dispersant functions maintains the fluidity of the mixture. 


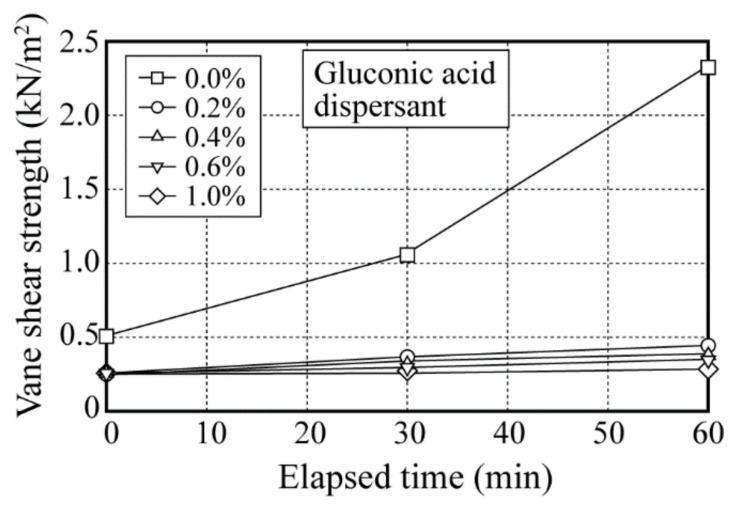

(a)

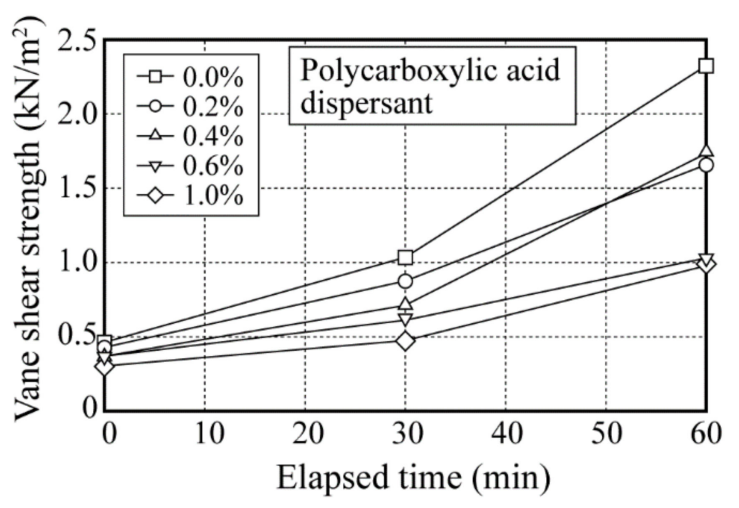

(b)

Figure 9. Effect of dispersant on increases in strength of the soil and binder mixture [14]. (a) Glycolic acid dispersant; (b) polycarboxylic acid dispersant.

\subsection{Injecting Atomized Cement Slurry}

A new type of construction machine is introduced, where cement slurry is accompanied by compressed air at the injection nozzle and atomized cement slurry is injected to mitigate the entrained rotation phenomenon, as shown in Figure 10 [16]. The injected air can function as a ball bearing to increase the fluidity of the soil and binder mixture. Figure 11 shows the stabilized soil strength distribution within the column obtained in field tests to compare the effect of atomized cement slurry injection (CI-CMC technique) and ordinary machines. The 28-day strength of the column stabilized by the ordinary machine shows a comparatively small strength on the order of 1000 to $1700 \mathrm{kPa}$, while that stabilized by the CI-CMC technique shows a large strength on the order of 3100 to $3600 \mathrm{kPa}$. The figure also shows that the strength variation of the CI-CMC technique is smaller than that of the ordinary machine. As a result, atomized cement slurry injection can function to keep the fluidity of fresh stabilized soil high, increase the strength, and decrease the strength variation.

Atomized cement slurry can disturb the soil structure and increase the fluidity of the soil and cement mixture, which can contribute to the decrease in the penetration resistance and required mixing energy and, in turn, the mixing machine can penetrate and mix a hard soil layer. Figure 12 shows the required auger torque to compare the CI-CMC and ordinary techniques [16]. In the case of the ordinary mixing machine, the mixing machine is stopped at the hard layer at a depth of approximately $-8 \mathrm{~m}$; however, the CI-CMC machine can penetrate through the hard layer. According to the case history, the CI-CMC technique can penetrate approximately $2.5 \mathrm{~m}$ into the mudstone layer with SPT N-values of approximately 25 to $50\left(q_{\mathrm{u}}=4\right.$ to $\left.5 \mathrm{MPa}\right)$. 


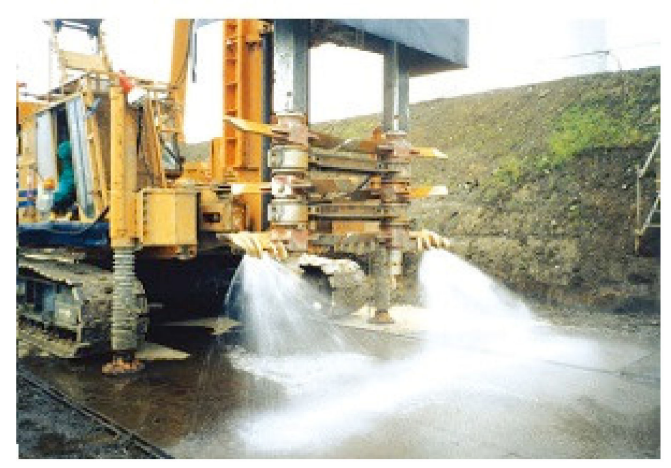

Figure 10. Mixing machine injecting atomized cement slurry [16].

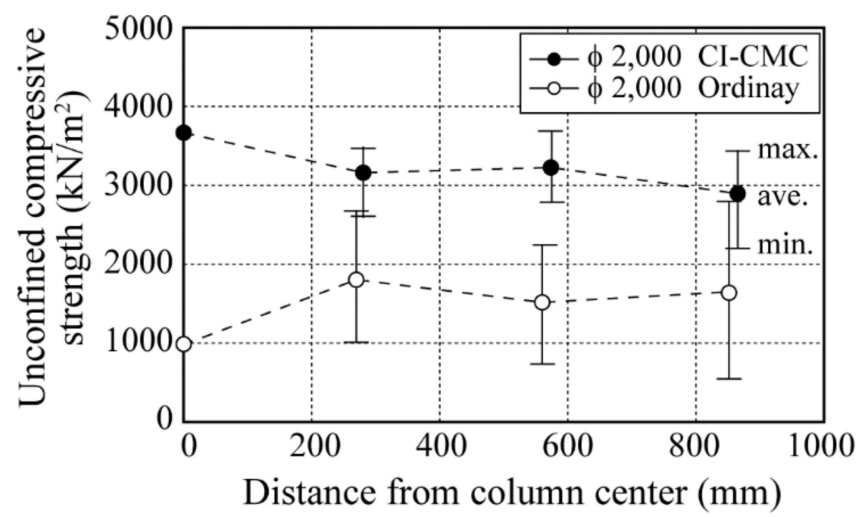

Figure 11. Stabilized soil strength distribution within the column [16].

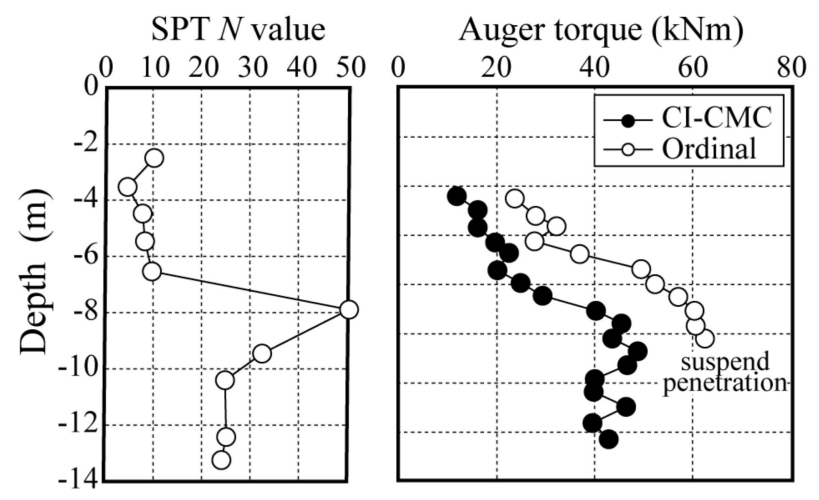

Figure 12. Effect of atomized cement slurry injection on penetration in the hard layer [16].

\section{Prediction of Field Strength by Construction Log Data and Future Perspectives}

\subsection{Relationship between the W/C Ratio and Stabilized Soil Strength}

There are many proposed formulas to predict the laboratory and field strengths [17-22]. Among them, one of the key parameters, the $W / C$ ratio, is introduced, which is defined as the total weight of water contained in the soil and binder slurry against the weight of the binder. The ratio is also expressed by the water content of soil, binder content, and water to binder ratio.

$$
\begin{gathered}
W / C=\left(W_{w s}+W_{w c}\right) / W_{c} \\
=(w / a w+w / c)
\end{gathered}
$$

where $a w=$ binder content, $w=$ water content of soil, $w / c=$ water to binder ratio of binder slurry, $W / C=$ total water to binder ratio, $W_{c}=$ dry weight of binder $(\mathrm{kg}), W_{w c}=$ weight of water contained in binder slurry $(\mathrm{kg})$, and $W_{w s}=$ weight of water contained in soil $(\mathrm{kg})$. 
Figure 13 shows an example of the relationship between the $W / C$ ratio and laboratory stabilized soil strength at 28 days of curing, $q_{\mathrm{u} 28}$, for various soils [23]. Furnace slag cement type $\mathrm{B}$ was used as a binder in the laboratory mix tests, where the cement dosage and the $w / c$ ratio of cement slurry were changed to cover a wide range of $W / C$ ratios. In the figure, test cases of the $w / c$ ratio of $100 \%$ are shown, where the original soils are classified into three groups depending on their fines content, $F c$ : 0 to $30 \%, 30$ to $70 \%$, and 70 to $100 \%$. The strength rapidly decreased with increasing $\mathrm{W} / \mathrm{C}$ ratio irrespective of the fine content. It was also found that the strength became larger when the fine content became large. A similar relationship has been found in various soils and binders stabilized by the deep mixing method [24] and pneumatic flow mixing method [25]. The stabilized soil strength can be formulated as Equation (7):

$$
q_{u}=a \times(W / C)^{b}
$$

where $a=$ parameter $(\mathrm{kPa}), b=$ parameter, and $q_{u}=$ unconfined compressive strength $(\mathrm{kPa})$.

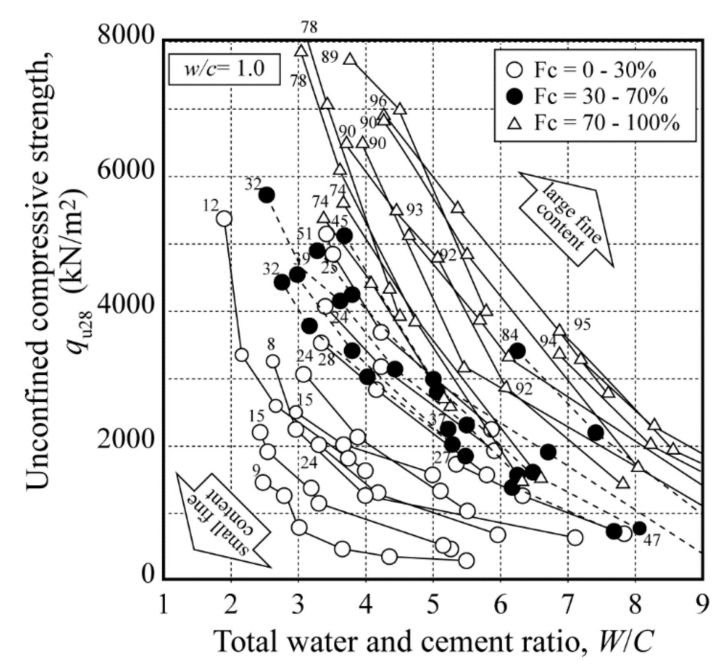

Figure 13. Relationship between the $W / C$ ratio and unconfined compressive strength [23].

The parameters $a$ and $b$ are influenced by the fines content, $F c$, where the value of $a$ increases as $F c$ increases, and the value of $b$ is negative and its absolute value decreases as $F c$ increases.

\subsection{Construction Log Data}

Figure 14 shows an example of deep mixing log data of a production column in a certain project. The mixing tool is equipped with two injection nozzles at the elevation of the bottom and top mixing blades for penetration injection and withdrawal injection, respectively. In Figure 14, the positions of the bottom and top mixing blades and the rotation speed of the mixing blade are plotted along the time of day. The ground at the construction site consists of four layers: the clay- 1 and clay-2 layers are soft layers with natural water contents of approximately $65-80 \%$, while the alluvial clay and alluvial sand layers are relatively hard layers with low natural water contents. Laboratory mix tests were carried out on the soils, and the relationships between the $W / C$ ratio by changing the cement dosage and the laboratory strength, $q_{u l}$, were examined to obtain parameters $a=37.8 \mathrm{MPa}$ and $b=-1.62$ for the clay and $a=16.7 \mathrm{MPa}$ and $b=-0.98$ for the sand in Equation (5). 


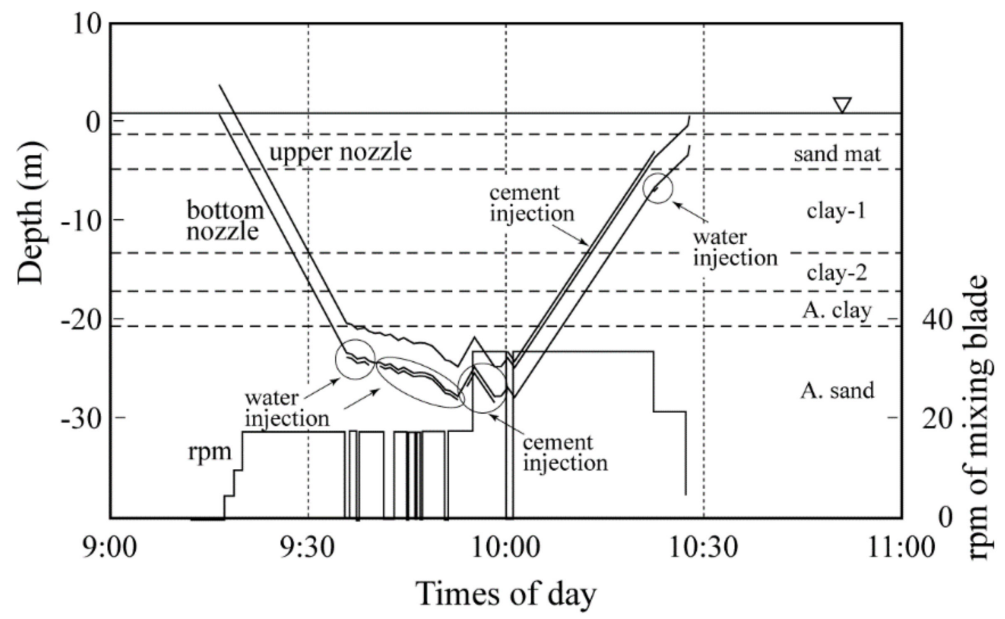

Figure 14. Example of DM construction log data.

In the production, as shown in Figure 14, the mixing tool penetrated clay-1, clay-2, and alluvial clay at a constant speed of $1 \mathrm{~m} / \mathrm{min}$, while the rotation speed of the mixing blade was kept almost constant at $18 \mathrm{rpm}$. When the bottom end of the mixing blade reached the alluvial sand layer at $-23.2 \mathrm{~m}$, the penetration speed was reduced to $0.13 \mathrm{~m} / \mathrm{min}$ due to the hard alluvial sand layer where the required torque of the mixing blade was increased. The mixing shaft continued to penetrate into the alluvial sand layer to a depth of $-27.5 \mathrm{~m}$ with a low penetration speed, while the mixing blade was rotated at a constant speed with several intentional stops. During penetration, water was injected approximately $1.1 \mathrm{~m}^{3}$ at depths of $-23.2 \mathrm{~m}$ to $-23.8 \mathrm{~m}$ and approximately $5.09 \mathrm{~m}^{3}$ at depths of -24.7 to $-27.5 \mathrm{~m}$ from the bottom nozzle for the purpose of softening the alluvial sand layer for ease of penetration. After reaching the design depth of $-27.5 \mathrm{~m}$, the mixing tool was moved up and down for the bottom treatment, while cement slurry of $80 \% w / c$ was injected from the bottom nozzle (penetration injection).

\subsection{Analysis of Construction Log Data}

The construction log data shown in Figure 14 were analyzed to evaluate the mixing condition every meter along the depth, and the analyzed result is shown in Figures 15-17. Figure 15 shows the distribution of the cement factor along the depth, which is defined as the weight of cement $(\mathrm{kg})$ over the soil volume $\left(\mathrm{m}^{3}\right)$. The cement factor is almost constant at approximately $150 \mathrm{~kg} / \mathrm{m}^{3}$ as the design criteria in the clay-1, clay-2, and alluvial clay layers. In the alluvial sand layer, the cement factor is scattered, ranging from 118 to $289 \mathrm{~kg} / \mathrm{m}^{3}$, as the cement slurry and water were injected for the bottom treatment and flushing the delivery tube.

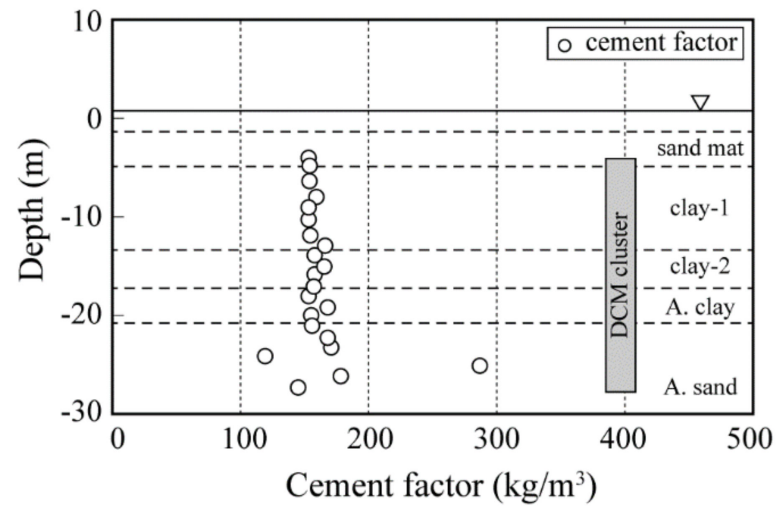

Figure 15. Distribution of binder factor along depth. 


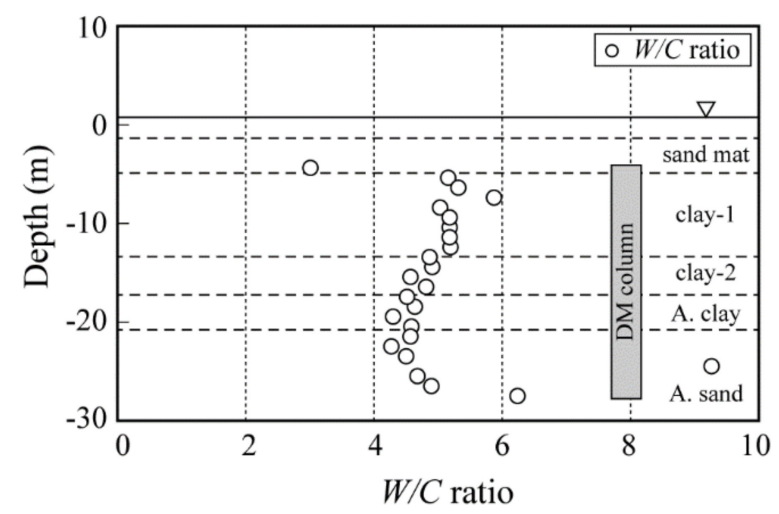

Figure 16. Distribution of W/C ratio along depth.

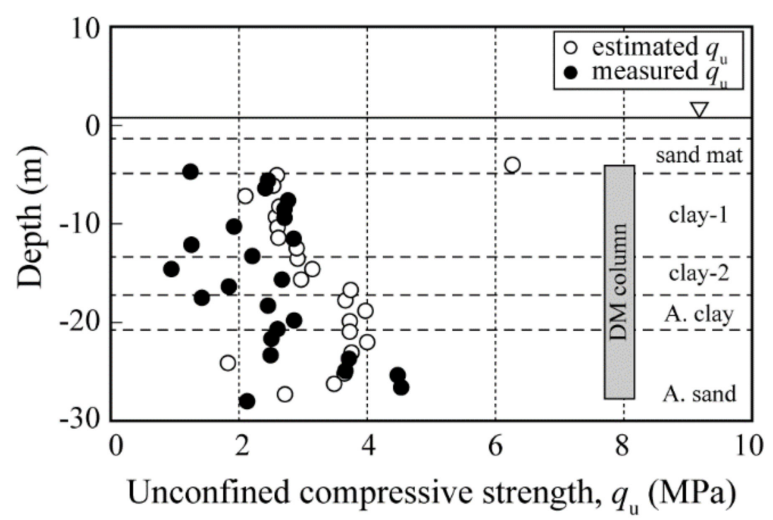

Figure 17. Distribution of predicted laboratory strength and measured field strength along depth.

The $W / C$ ratio was calculated by Equation (4) using the estimate water content of soil at the depth and plotted along the depth in Figure 16. In the clay- 1 layer, the $W / C$ ratio is almost constant at approximately 4.8 , except at approximately $-7 \mathrm{~m}$, where $0.48 \mathrm{~m}^{3}$ of water was injected to flush the delivery tube after the withdrawal injection. In the clay- 2 and alluvial clay layers, the $W / C$ ratio is smaller than that of the clay- 1 layer, even though the amount of cement is almost the same, which is due to the low natural water content of the layers rather than that of the clay- 1 layer. The $W / C$ ratio in the alluvial sand layer is scattered from 4.3 to 9.3 , which is due to the scatter in the amount of injected cement slurry and water.

The estimated unconfined compressive strength of laboratory soil, $q_{u l}$, is shown along the depth in Figure 17. The predicted strength at a depth of approximately $-7 \mathrm{~m}$ is approximately $2.1 \mathrm{MPa}$, which is approximately $20 \%$ smaller than that of the others and is due to the water injection there. In the alluvial clay layer, the predicted strength is almost constant at approximately $3.9 \mathrm{MPa}$. In the alluvial sand layer, the predicted strength decreases with depth. The estimated strength at a depth of approximately $-26.0 \mathrm{~m}$ is quite small at approximately $1.9 \mathrm{MPa}$.

The core sample was taken from the column, and unconfined compression tests were carried out to measure the field strength, $q_{u f}$. These measured strengths are plotted in Figure 17 by solid circles. The measured strengths in clay- 1 and clay- 2 are smaller than the estimated strength. The ratio of the measured and estimated strength, $q_{u f} / q_{u l}$, is roughly obtained as approximately 0.63 . It should be noted that the measured strength is scattered rather than the estimated strength, which might be due to the local soil condition, mixing condition (entrained rotation phenomenon), and the coring and unconfined compression testing machine and techniques. 


\subsection{Future Perspectives}

As described above, the $W / C$ ratio has a close relationship with the unconfined compressive strength and can be applied in QC/QA during construction to assure the design strength. Many construction parameters are continuously measured during the production in Japan, which includes plotting the position of mixing shaft, penetration and withdrawal speeds of mixing shaft, rotation speed of mixing blade, electric current for driving mixing blade, lifting load of mixing blades, and accumulated cement volume. It is possible to estimate the soil type and water content at each depth based on their measured values, and the field-stabilized soil strength can be estimated by Equations (4) and (5). Once the strength during production has been predicted, several countermeasures can be adopted and carried out during production to assure the design criteria.

In fact, many attempts have been made to estimate the types and properties of ground from the construction log data in several ground improvement methods. However, due to the errors and scatters in the measured data and large variations in ground properties, it was not possible to estimate them with acceptable accuracy. It is expected that the types and properties of ground can be estimated by referring to a vast database using AI system in near future. In recent years, information communication technology (ICT) has been applied in the construction industry to increase the productivity and reliability of construction. ICT construction machines feature advanced technology, such as machine guidance systems and production control systems, to assist the operator and site management systems in processing productivity and work progress data.

\section{Concluding Remarks}

In the manuscript, the current practice of quality control and assurance was briefly introduced based on the Japanese experience/results with mechanical mixing technology by vertical shaft mixing tools with horizontal rotating circular mixing blade. The QC/QA practice comprises laboratory mix tests, field trial tests, monitoring, and control of construction parameters during production and verification by the engineering characteristics of stabilized soil.

It is well known that field-stabilized soil columns/elements have relatively large strength variability. One of the reasons behind the strength variability is the type of soil. Some cohesive soils are so sticky that the soil and binder mixture adheres to and rotates with the mixing blade without efficient mixing. For such soils, several alternative approaches are introduced in the manuscript: using a new type of special cement, injecting chemical additives, and injecting air.

The $W / C$ ratio had a close relationship with the unconfined compressive strength and can be applied in QC/QA during construction to assure the design strength. The fieldstabilized soil strength could be estimated by the production log data during production. Once the strength during production is predicted, several countermeasures can be adopted and carried out during production to assure the design criteria.

As ICT and AI technologies are developed very rapidly, ICT deep mixing equipment will be working on site to produce stabilized soil columns/elements in the near future. In the machine, the type and properties of the ground profile are estimated by the measured construction control parameters (such as the hanging load, penetration speed of the mixing tool, and driving torque of the mixing blade in the penetration stage) and the appropriate mixing conditions (such as the amount of binder and blade rotation number, obtained with the help of the $W / C$ concept and the accumulated database), together with AI technology to achieve the design strength along the depth. The stabilized soil column is produced automatically by ICT deep mixing equipment according to the obtained mixing conditions.

It is noted that the conclusions presented here are only valid for these specific conditions, therefore any extrapolation to other DM techniques should be made with caution requiring more studies. 
Funding: This research received no external funding.

Institutional Review Board Statement: Not applicable.

Informed Consent Statement: Not applicable.

Data Availability Statement: Not applicable.

Conflicts of Interest: The author declares no conflict of interest.

\section{References}

1. Kitazume, M.; Terashi, M. The Deep Mixing Method; CRC Press, Taylor \& Francis Group: Boca Raton, FL, USA, 2013; 410p.

2. Terashi, M.; Kitazume, M. Current Practice and Future Perspective of QA/QC for Deep-Mixed Ground. In Proceedings of the International Symposium on Deep Mixing and Admixture Stabilization, Okinawa, Japan, 19-21 May 2009; pp. 61-99.

3. Cement Deep Mixing Method Association. Cement Deep Mixing Method (CDM) Design and Construction Manual; Cement Deep Mixing Method Association: Tokyo, Japan, 1999. (In Japanese)

4. $\quad$ Deere, D.U. Rock Quality Designation (RQD) after 20 Years; U.S. Army Corps of Engineers: Washington, DC, USA, 1989.

5. Dry Jet Mixing Method Association. Dry Jet Mixing (DJM) Method Technical Manual; Dry Jet Mixing Association: Narita, Japan, 2006. (In Japanese)

6. JACSMAN Association. Technical Data for JACSMAN, Ver. 6; JACSMAN Association, KU Publisher: Tokyo, Japan, 2011; 21p. (In Japanese)

7. Terashi, M. The state of practice in deep mixing method. Grouting and ground treatment. ASCE Geotechnical Special Publication No. 120;. In Proceedings of the 3rd International Conference on Grouting and Ground Treatment, New Orleans, LA, USA, 10-12 February 2003; Volume 1, pp. 25-49.

8. Coastal Development Institute of Technology. Technical Manual of Deep Mixing Method for Marine Works, Revised Version; Coastal Development Institute of Technology: Tokyo, Japan, 2008; 289p. (In Japanese)

9. Public Works Research Center. Deep Mixing Method Design and Execution Manual for Land Works; Public Works Research Center: Narita, Japan, 2004; 234p. (In Japanese)

10. Hosoya, Y.; Nasu, T.; Hibi, Y.; Ogino, T.; Kohata, Y.; Makihara, Y. Japanese Geotechnical Society Technical Committee Reports: An evaluation of the strength of soils improved by DMM. In Proceedings of the Second International Conference on Ground Improvement Geosystems, Tokyo, Japan, 14-17 May 1996; Volume 2, pp. 919-924.

11. Halkola, H. Keynote lecture: Quality control for dry mix method. In Dry Mix Methods for Deep Stabilization; Routledge: London, UK; A.A. Balkema: Rotterdam, The Netherlands, 1999; pp. 285-294.

12. Larsson, S. State of Practice Report-Execution, monitoring and quality control. In Proceedings of the International Conference on Deep Mixing-Best Practice and Recent Advances, Stockholm, Sweden, 23-25 May 2005; Volume 2, pp. 732-785.

13. Aoyama, K.; Miyamori, T.; Wakiyama, T.; Kikuchi, D. The Influence of Physico-Chemical Property on Improved Soil Character. J. Jpn. Soc. Civ. Eng. 2002, 2002, 207-219. (In Japanese)

14. Mizutani, Y.; Makiuchi, K.; Minegishi, K. Effects of Surfactant Additive on Strength Stability of Soil Cement Pile; Japanese Geotechnical Society: Tokyo, Japan, 2003; pp. 1047-1048. (In Japanese)

15. Hirano, S.; Mizutani, Y.; Nakamura, H.; Shimomura, S.; Sasada, H. Quality Improvement of Deep Mixing Method by Dispersant Additives; Japanese Geotechnical Society: Tokyo, Japan, 2015; pp. 881-882. (In Japanese)

16. Japan Cement Association. Soil Improvement Manual Using Cement Stabilizer, 3rd ed.; Japan Cement Association: Tokyo, Japan, 2007; 387p. (In Japanese)

17. Murakami, S. Deep mixing method using ejector discharge injection and new construction management system-CI-CMC Method. Kisoko 2017, 6, 44-47. (In Japanese)

18. Tsuchida, T.; Tang, Y.X. A consideration on estimation of strength of cement-treated marine clays. Jpn. Geotech. J. 2012, 7, 435-447. (In Japanese) [CrossRef]

19. Horpibulsuk, H.; Miura, N.; Nagaraj, T.S. A new method for predicting strength of cement stabilized clays. In Proceedings of the International Conference on Coastal Geotechnical Engineering in Practice, Yokohama, Japan, 20-22 September 2000; Volume 1, pp. 605-610.

20. Tang, Y.X.; Miyazaki, Y.; Tsuchida, T. Advanced reuses of dredging by cement treatment in practical engineering. In Proceedings of the International Conference on Coastal Geotechnical Engineering in Practice, Yokohama, Japan, 20-22 September 2000; Volume 1, pp. 725-731.

21. Yanagihara, M.; Horiuchi, S.; Kawaguchi, M. Long-term stability of coal-fly-ash slurry manmade island. In Proceedings of the International Conference on Coastal Geotechnical Engineering in Practice, Yokohama, Japan, 20-22 September 2000; Volume 1, pp. 763-769.

22. Miyazaki, Y.; Tang, Y.X.; Ochiai, H.; Yasufuku, N.; Omine, K.; Tsuchida, T. Utilization of cement treated dredged soil with working ship. J. Jpn. Soc. Civ. Eng. 2003, 2003, 193-204. (In Japanese)

23. Yoneda, K. Examination of strength characteristics of cement stabilized soils. In Technical Forum; Japan Geotechnical Consultants Association: Tokyo, Japan, 2011. (In Japanese) 
24. Federal Highway Administration. Design Manual: Deep Mixing for Embankment and Foundation Support; Federal Highway Administration: Washington, DC, USA, 2013; 228p.

25. Kitazume, M.; Satoh, T. Development of Pneumatic Flow Mixing Method and its Application to Central Japan International Airport Construction. J. Ground Improv. 2003, 7, 139-148. [CrossRef] 